\title{
Stability of the effect of silencing genes involved in the midgut homeostasis on Anopheles arabiensis mosquito reared under different breeding site conditions
}

\section{Serkadis Debalke}

Jimma University

Tibebu Habtewold ( $\nabla$ t.habtewold@ic.ac.uk)

Imperial College London https://orcid.org/0000-0002-5427-8396

George K. Christophides

Imperial College London

Luc Duchateau

Universiteit Gent

Research

Keywords: Anopheles arabiensis, larval breeding sites, survival, gene silencing stability

Posted Date: January 24th, 2020

DOl: https://doi.org/10.21203/rs.2.21780/v1

License: (c) (i) This work is licensed under a Creative Commons Attribution 4.0 International License.

Read Full License

Version of Record: A version of this preprint was published at Parasites \& Vectors on April 19th, 2020. See the published version at https://doi.org/10.1186/s13071-020-04078-2. 


\section{Abstract}

Background: Malaria vector mosquitoes acquire midgut microbiota primarily from their habitat. The homeostasis of these microbial communities plays an essential role in the mosquito longevity, the most essential factor in the mosquito vectorial capacity. Our recent study revealed that silencing genes involved in regulation of the midgut homeostasis including FN3D1, FN3D3, and GPRGr9 reduced the survival of female adult Anopheles arabiensis mosquito. In the present study, we investigate the stability of the gene silencing efficiency of mosquitoes reared in three different breeding conditions representing distinct larval habitat types: town brick pits in Jimma, flood pools in the rural land of Asendabo and roadside pools in Wolkite.

Methods: First instar larvae of $A n$. arabiensis mosquitoes were reared separately using water collected from the three breeding sites. The resulting adult females were micro-injected with dsRNA targeting the FN3D1 gene (AARA003032) and their survival was monitored. Control mosquitoes were injected with dsRNA Lacz. In addition, the load of midgut microbiota of these mosquitoes was determined using flow cytometry.

Result: Survival of naïve adult female mosquitoes differed between the three sites. Mosquitoes reared using water collected from brick pits and flood pools survived longer than mosquitoes reared using water collected from roadside. However, the FN3D1 gene silencing effect on survival did not differ between the three sites.

Conclusion: The present study revealed that the efficacy of FN3D1 gene silencing is not affected by variation in the larval habitat. Thus, silencing this gene using genetic engineering approaches can have a large potential for application throughout sub-Saharan Africa.

\section{Introduction}

Malaria still thrives in sub-Saharan Africa. The region holds over $90 \%$ of the 219 million malaria cases with an estimated 435,000 malaria deaths in 2017 [1]. This disproportionate share is due to the principal malaria vectors in the region that exhibit a higher vectorial capacity, i.e., Anopheles gambiae (s.s.), Anopheles coluzzii, Anopheles arabiensis and Anopheles funestus.. Key parameters for vectorial capacity include preference to feed on humans, susceptibility to Plasmodium infection and longevity of the mosquito. It can take two weeks and beyond for the Plasmodium parasites to complete the mosquito stage development after which they can be transmitted to another human host. On the other hand, in tropical regions, the average lifespan of Anopheles mosquitoes is 14 to 19 days [2, 3], resulting in only a few long-living vectors that can transmit malaria. Therefore, a promising strategy to eliminate malaria transmission is to reduce the mosquito lifespan, as even a small reduction would have a large impact on transmission [4]. 
Adult mosquito survival is influenced by the environment during the preceding immature stage. Environmental factors consist of the physicochemical characteristics of larval habitats $[5,6]$, and the quality and availability of nutrients $[7,8]$. Previous studies have demonstrated that larval fitness has a major effect on the adult survival of different malaria mosquitoes [8-11]. For instance, female adult mosquitoes maintained in a high nutritive larval environment lived longer than in a poor nutritive environment $[9,12]$. A nutritionally restrictive larval environment yields mosquitoes with reduced size with significantly shorter survivorship $[9,10]$. Microorganisms and organic materials in the larval pool are the major constituents of the larval diet [13]. Previous studies have demonstrated that bacteria in the breeding water are most critical for the quality of the larval diet and their absence leads to increased larval mortality [14-17].

An increasingly important factor that affects the life trait of adult mosquitoes is the pollution of the larval habitats. Rapid and unplanned expansion of urbanization in sub-Saharan Africa increases pollution of the surface waters with domestic or industrial discharges of untreated effluents [18-19]. The Anopheles larvae have shown a high resilience to the high toxicity of some of these wastes in the urban and suburban sites, but the impact of such pollution on the life trait of the resulting adult mosquito is poorly understood. However, there is speculation that exposure of larvae to toxins dissolved in the water might contribute to the rising prevalence of vector resistance to pyrethroids in the cities across the region [2021]. It was also suggested that larvae developing in polluted water can lead to a significant fitness cost [22].

Based on the above facts, we assessed the survival of adult female Anopheles arabiensis mosquitoes reared in water collected from three different breeding sites. In our previous study we observed that silencing the midgut gene Fibronectine Family III(FN3D1) reduced the longevity of An. arabiensis mosquitoes [23]. Therefore, in the present study we further assessed the stability of the FN3D1 gene silencing effect on An. arabiensis mosquitoes reared in water collected from three different breeding sites.

\section{Methods}

\section{Study sites and sample collection}

Water samples for mosquito rearing were collected from three malaria endemic sites including Wolkite, Jimma and Asendabo, Southwest Ethiopia (altitude/latitude $7040^{\prime} 0.01$ " N, 36 49' 59.99" E) (Fig. 1). From each site, a single pool confirmed to support An. arabiensis larvae was selected to collect rearing water using a clean jug and plastic container/jerry cans independently. Simultaneously water samples for bacterial count were collected using sterile, screw cup bottles following standard operational procedures [24]. The water collected for rearing purpose was filtered using a fine mesh linen cloth in order to remove debris and mosquito eggs and larvae. The filtered water was then transferred directly to clean larvae rearing pan or boiled for $10 \mathrm{~min}$ and cooled before transferring to the rearing pans. 


\section{Analysis Of Water From Selected Sites}

$\mathrm{PH}$, conductivity and dissolved oxygen was measured on site using a Portable Multi meter (HQ40D, $\mathrm{HACH}$ ). Salinity was measured using a salinity meter (TRACER PocketTester) and turbidity with a turbidity meter (Wag-WT 3020, Wagtech International). Total dissolved solids (TDS) and total suspended solids (TSS) were measured by the gravimetric method. In brief a volume of $100 \mathrm{ml}$ of well-mixed water samples was filtered using a glass-fiber-filter with applied vacuum. The filtered samples were then washed with three successive $10 \mathrm{ml}$ volumes of distilled water which permitted complete drainage between washings. The suction was continued for about 3 minutes after filtration was completed. The filtrate (with washing) was then transferred to a weighed evaporating dish and evaporated to dryness on a steam bath. If the filtrate volume exceeded dish capacity successive portions were added to the same

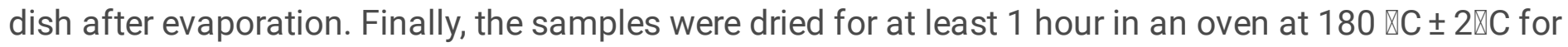
TDS and $103-105^{\circ} \mathrm{C}$ for TSS, allowed to cool in a desiccator to balance temperature, and weighed [24]. All the parameters were measured based on the supplier's guidelines and the instruments were calibrated before the samples analysed. A total of two replicates was taken for each site.

The total bacterial count was assessed for the water samples using membrane filter techniques. In short, $0.5 \mathrm{ml}$ of the water sample was diluted with sterilized distilled water with a total volume of $100 \mathrm{ml}$ and allowed to pass through a funnel covered with a membrane filter (with a size of $47 \mathrm{~mm}$ diameter by $0.45 \mu \mathrm{m}$ porosity) in order to trap the bacteria available in the water. Then the membrane with the trapped bacteria was placed in a Petri dish containing a pad saturated with sterilized M-lauryl sulfate broth (Sigma Aldrich, India). The M-lauryl sulfate broth media was prepared according to the manufacturer's guideline. The passage of nutrients through the filter during incubation facilitates the growth of organisms in the form of colonies on the upper surface of the membrane. Then, the inoculates were incubated at a temperature of $37^{\circ} \mathrm{C}$ for 24 hours where after the total number of the colonies was counted using a magnifying lens [24].

\section{Mosquito Rearing}

An. arabiensis obtained from a laboratory strain of the Adama Malaria Research Centre, Ethiopia, was used in this study. Just hatched 1 st larvae were reared in the water collected from the three breeding sites. Two-hundred larvae from the same batch of eggs were dispensed into the rearing trays and supplied with an equal amount of a mixture of yeast and fish food. The rearing water was changed every two days and development of larvae was monitored daily. Next, the enclosed pupae were counted and transferred into $10 \mathrm{ml}$ glass beakers independently and kept in adult cages $(\mathrm{W} 15 \times \mathrm{D} 15 \times \mathrm{H} 15$ $\mathrm{cm}$,BugDourm BD4F2222) until the emergence of the last pupae. The emerged adults were maintained on

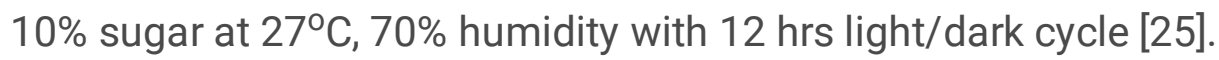

Adult wing size was measured to evaluate differences in the adult female body size. For this experiment 10 individual mosquitoes were removed from each adult cage to measure their wing size as follows: a 
single wing was clipped from each mosquito using scalpel blade and mounted onto a glass microscope slide. Then the wing size was measured using a micrometer eyepiece with sterio-microscope.

Measurements were taken from the tip of the wing (excluding fringe) to the distal end of the alula [26].

\section{Gene silencing and survival assay}

From each breeding site, 15-24 adult female mosquitoes were $\mathrm{CO} 2$ anesthetized and treated with $69 \mu \mathrm{l}$ of the FN3D1 dsRNA gene and another group with non-mosquito dsLacZ gene. Double stranded RNA (DsRNA) for FN3D1 and the control LacZ gene was prepared from complementary DNA (cDNA) as described in our previous study [23]. The cDNA was synthesized from $1 \mu \mathrm{g}$ of the tRNA (using PrimeScript $^{\text {TM }} 1$ st -strand cDNA Synthesis Kit (TaKaRa, UK) which was extracted from 10 whole female An. arabiensis mosquitoes using TRIzol reagent (Life Technologies, UK). The following primer sequences tailed with the T7 promoter were used to synthesize the two dsRNA:FN3D1 F: GATGGACGTGGATCAGCC R: TGGATCGTCCTCATCACTGT and LacZ F: AGAATCCGACGGGTTGTTACT R: CACCACGCTCATCGATAATTT.

On day four, after the mosquitoes were starved overnight, they were fed on blood. At 24 hours post blood meal, 5 mosquitoes were sampled for each breeding site independently for both unboiled and boiled water and their midguts were dissected. The midgut samples were then homogenized in $100 \mu \mathrm{l} \%$ Paraformaldehyde (PFA) in Phosphate-buffered saline (PBS). The number of bacteria was then counted using flow cytometry from five pooled midgut samples per replicate [27]. A total of 3 replicates of microbiota analysis were performed.

The survival of mosquitoes was monitored starting from 24 hrs post injection for 20 days. All mosquitoes were supplied with $10 \%$ sugar solution and monitored daily, and they obtained blood meal at 4 days intervals post injection. Three replicates each consisting of 15-24 mosquitoes were performed.

\section{Data analysis}

Data analysis was performed using the statistical software package R version 3.3.2. Survival of the FN3D1 gene and LacZ gene silenced mosquitoes and the naïve mosquitoes with boiled and unboiled water were depicted by Kaplan Meier survival curves as a function of site. The effect of gene silencing on survival was modelled by the Cox proportional hazards frailty model [28]. with replicate as frailty term and including as covariates the gene (the FN3D1 target and LacZ control gene), the site (Jimma, Asendabo and Wolkite) and the two-way interaction. The effect of site and boiling in the naïve mosquito was analysed in the same way. The hazard ratio was used as summary statistic, together with the median time to death. The bacterial counts were first log transformed and then compared by a mixed model with replicate as random effect and the F-test was used to compare the silencing of the FN3D1 target gene and the control LacZ gene on the one hand, and the boiling on the other hand. The ratio of the bacterial counts in the control LacZ gene and the FN3D1 target gene was used as summary statistic. The T-test was used to compare the number of emerged adults and pupae between the three breeding sites. All tests were done at a significance level of $5 \%$. 


\section{Results}

\section{Analysis of water samples}

Pictures of the three breeding sites are shown in Fig. 2 and their physicochemical characteristics in Table 1. The water for the Jimma and Asendabo sites were close to the neutral PH, while the Wolkite site was inclined to be alkaline with the highest salinity. Nevertheless, the PH for all the sites was within a range that was previously reported suitable for the natural breeding habitats of the An. arabiensis mosquitoes [29]. The level of dissolved oxygen was considerably higher for the Wolkite and the Asendabo sites compared to the Jimma site. The Asendabo site had also the highest total bacterial count compared to Jimma or Wolkite sites.

Table 1

Physicochemical characteristics and bacterial count of water samples from the three sites. The data are presented as median (range).

\begin{tabular}{|llll|}
\hline Parameters & Wolkite & Jimma & Asendabo \\
\hline PH & $8.2(7.9-8.5)$ & $7.3(7.1-7.5)$ & $7.15(7.0-7.4)$ \\
\hline Salinity $(\mathrm{ppm})$ & $225(180-320)$ & $85(75-125)$ & $160(100-175)$ \\
\hline DO(mg/l) & $7.2(2.3-7.6)$ & $4.5(1.8-8.8)$ & $6.3(5.1-9.0)$ \\
\hline Turbidity & $27.3(4.9-80.2)$ & $51.7(2.2-87.1)$ & $64.35(47.25-146)$ \\
\hline TDS $(\mathrm{mg} / \mathrm{l})$ & $507.5(256-665.5)$ & $237(185.5-317)$ & $167(163-256.2)$ \\
\hline TSS $(\mathrm{mg} / \mathrm{l})$ & $157.5(72-358)$ & $275.5(156-293)$ & $170(151-323)$ \\
\hline Chlorophyl a & $11.6(11.3-12.0)$ & $11.9(11.7-12.3)$ & $12.2(12.0-12.4)$ \\
\hline Bacterial count $\left(10^{3} \mathrm{CFU} / 100 \mathrm{ml}\right)$ & $317(233-400)$ & $233(192-291)$ & $546(252-660)$ \\
\hline DO: Dissolved Oxygen; TDS: Total Dissolved Solids; TSS: Total Suspended Solid \\
\hline
\end{tabular}

\section{Larval Development}

Our results demonstrated that the larvae reared with water from Asendabomarkedly outperformed the rest with regard to pupation rate, the proportion of pupae resulting in viable adults and the adult body size (Table 2). For instance, the pupation rate for Asendabo (85.8\%) was significantly higher compared to Wolkite (68.5\%) $(P=0.01)$ and Jimma (78\%) $(P=0.008)$ A significantly higher percentage of pupae developed in adult mosquitoes for Asendabo compared to Wolkite $(P=0.008)$ and Jimma $(P=0.005)$. The mean adult wing size was the longest for Asendabo $(3.2 \mathrm{~mm})$ followed by Jimma $(3.0 \mathrm{~mm})$ and Wolkite $(2.7 \mathrm{~mm})$. Together, the above parameters are positively associated with the level of dissolved 
oxygen and bacterial count in the breeding water. Accordingly, the water from Asendabo is most suitable for larval development.

Table 2

The rates of pupation and adult emergence, and the mean adult wing size $(\mathrm{n}=30)$ (in $\mathrm{mm}$ ) in mosquitoes reared in the water collected from the three sites.

\begin{tabular}{|llll|}
\hline Breeding Site & Pupa No(\%) & Adult No (\%) & Wing Size \\
\hline Wolkite & $413(68.5)$ & $387(87.7)$ & 2.7 \\
\hline Jimma & $469(78)$ & $439(93.6)$ & 3.0 \\
\hline Asendabo & $515(85.8)$ & $494(95.9)$ & 3.2 \\
\hline
\end{tabular}

\section{Survival Rate Of Adult Mosquitoes}

Survival of the mosquitoes is depicted as a function of time in Fig. 3 for the different settings, i.e., different sites and water boiled or not. There was no significant interaction between the site and boiling effect, i.e., the effect of boiling the water has a similar effect for the three sites. A significant effect of boiling the water $(P=0.001)$ and an almost significant difference between the sites $(P=0.059)$ was found. The hazard ratio of the mosquitoes grown in boiled water compared to unboiled water equals 2.25 (95\% Cl: [ $1.42 ; 3.56])$. The hazard ratio of Jimma compared to Wolkite equals 0.53 (95\% Cl: [0.32;0.88]) whereas the hazard ratio of Asendabo compared to Wolkite equals 0.51 ( $95 \% \mathrm{Cl}$ : [0.31; 0.84]). The adult gut bacterial count ratios in mosquitoes grown in the unboiled versus the boiled water for the three sites is presented in Fig. 4.

\section{Effect of the FN3D1 gene silencing}

Survival of the FN3D1 and LacZ silenced mosquitoes is depicted as a function of time in Fig. 5 for the different sites. There was no significant interaction between the gene silencing effect and the site, i.e., the effect of silencing is the same for the three sites. Both gene silencing $(P<0.001)$ and site $(P=0.017)$ had a significant effect on survival. The hazard ratio of the FN3D1 silenced mosquitoes compared to the LacZ silenced mosquitoes equals 1.96 (95\% Cl: [ 1.58; 2.43]). The hazard ratio of Jimma compared to Wolkite equals 0.69 (95\% Cl: [0.54;0.89]) whereas the hazard ratio of Asendabo compared to Wolkite equals 0.86 (95\% Cl: $[0.67 ; 1.10])$.

Significant effects for the microbiota were found for the gene silencing $(P=0.016)$ and for the interaction between gene silencing and site $(P=0.038)$. Therefore, we study the gene effect at each location separately. A significantly higher bacterial load in the FN3D1 silenced mosquitoes as compared to the 
LacZ silenced mosquitoes was only found for Asendabo, with a ratio equal to 2.50 which differs significantly from $1(P=0.002)$ (Fig. 6).

\section{Discussion}

In the present study, we demonstrated that the larval breeding habitats in the three sites vary distinctly with regard to their physico-chemical characteristics and microbial abundance.

Previous studies have demonstrated that the physico-chemical characteristics [30-32] of the larval breeding habitat determine the larval and pupal density, the size and number of emerged adults and the survival of both larvae and adult mosquitoes. Thus, the mosquitoes in the study sites could also differ in their fitness (e.g. size, longevity, fecundity) and capacity to support and transmit the malaria parasite [8, 10]. Previous studies have shown that different species of mosquitoes maintained and reared in low food environments had a reduced longevity, smaller body size and lower vectorial capacity [8, 9, 31, 33, 34]. Most mosquito life traits (fitness) are affected by environmental factors, and specifically the breeding habitat $[8-10,35,36]$.

The present observation of an increased total number of emerged mosquitoes for the larvae that were reared in water collected from Asendabo is an indicator for a higher suitability of that larval habitat. For this site, two parameters that stand out include a high bacterial abundance and increased oxygenation. Previous studies have established that bacteria in the breeding habitat constitute the main food source for larvae enhancing larval growth and the productivity and survival of the adult mosquitoes $[8,9,17]$. Studies have also demonstrated that higher dissolved oxygen favours the development of Anopheles mosquitoes [37, 38].

In this study wing size of the adult female mosquitoes was measured because the wing size is also an indicator for the suitability of the larval breeding environment. Our data revealed there is a marked variation in the wing size between the mosquitoes originating from different breeding sites with the Asendabo site yielding mosquitoes with the largest wing compared to Jimma and Wolkite. A similar variation in the wing size among the mosquitoes grown in different larval habitats was reported earlier for Anopheles stephensi [9] and Anopheles darlingi $[8,39]$. It was concluded that such variation in the wing size is closely linked to the nutrient availability in the habitat $[8,9]$.

Wing size is directly correlated with survival of adult female mosquitoes, i.e., the mosquitoes with longer wing showed a higher longevity than short winged mosquitoes $[9,12,40,41]$. Comparison of the survival of the mosquitoes reared with water from the three sites in the present work was supported by the above observation. For instance, the mosquitoes reared in the water from the Asendabo site that had the longest wing displayed the longest survival.

Previously we have demonstrated that the depletion of some midgut gene proteins including the FN3D1, FN3D3 and GPRGr9 genes markedly shorten the longevity of female An. arabiensis [23]. In the present study, we assessed whether the variation between breeding habitats may affect the gene silencing effect. 
Our survival data revealed that the effect of gene silencing was not affected by variation in the larval breeding site, i.e. for all the study sites the FN3D1 treated mosquitoes had a similarly reduced survival rate compared to the control LacZ group. Thus, the variation in breeding sites does not affect the gene silencing effect on reducing the longevity of An. arabiensis mosquitoes. Gene silencing induces mosquito mortality by disrupting the midgut homeostasis [23], which is evidenced also in the present work where a higher bacterial load was observed in the FN3D1 silenced mosquitoes as compared to the LacZ silenced mosquitoes.

\section{Conclusion}

The longevity of the An. arabiensis mosquitoes varied between the three larval breeding sites depending on biotic as well as abiotic characteristics of the larval breeding water. However, there was no evidence that these differences compromise the gene silencing effect of the FN3D1 gene on the mosquito survival. Therefore, interventions based on the silencing of such genes, and thus the reduction of mosquitoe's longevity, offer a universal strategy to block malaria transmission.

\section{Abbreviations}

cDNA:complementary DNA; DNA:Deoxyribonucleic acid; DO:Dissolved Oxygen; dsRNA:double stranded RNA; FN3D1:Fibronectin type III domain- protein 1; FN3D3:Fibronectin type III domain- protein 3; GPRGR9:G protein coupled receptor protein 9; PBS:Phosphate-buffered saline; PFA:Paraformaldehyde; RNA:Ribonucleic acid; TDS:Total Dissolved Solid; TSS:Total Suspended Solid

\section{Declarations}

\section{Ethical clearance}

Ethical clearance was obtained from the research and ethical review board of Agriculture and Veterinary Medicine, Jimma University.

\section{Consent for publication}

Not applicable.

\section{Availability of data and material}

Datasets are available from the corresponding author on reasonable request.

\section{Competing interests}

The authors declare that they have no competing interests.

\section{Funding}


This study was funded by the Institutional University Cooperation IUC-JU project in the framework of the Flemish Interuniversity Council (VLIR-UOS).

\section{Authors' contributions}

TH, LD and GKC developed the research idea. SD and TH performed the mosquito field studies. TH and SD took care of all lab analyses. LD analyzed and interpreted the data. All authors were involved in writing and read and approved the final manuscript.

\section{Acknowledgements}

We acknowledge the financial support from the Institutional University Cooperation IUC-JU project to LD, in the framework of the Flemish Interuniversity Council (VLIR-UOS). The project was additionally supported by the Welcome Trust Investigator Award to GKC, and at late stages, by the Bill and Melinda Gates Foundation grant OPP1158151 to GKC.

\section{References}

1. WHO. World Malaria Report. 2018 Accessed on June 2019.

2. Gillies MT and Wilkes TJ. A study of the age-composition of populations of Anopheles gambiae giles and Anopheles funestus Giles in North-Eastern Tanzania. Bull Entomol Res. 1965; 56:237-262. doi:10.1017/S0007485300056339.

3. Service MW and Towson H. "The Anopheles vector," in Essential Malariology Warrell DA and Gilles HM, Eds., pp. 59-84, Arnold, London, UK, 2002.

4. Smith DL and McKenzie EF. Statics and dynamics of malaria infection in Anopheles mosquitoes. Malar J. 2004; 3:13. doi:10.1186/1475-2875-3-13.

5. Oyewole IO, Momoh OO, Anyasor GN, Ogunnowo AA, Ibidapo CA, Oduola OA, et al. Physico-chemical characteristics of Anopheles breeding sites: Impact on fecundity and progeny development. Afr J Environ Sci Technol. 2009; 3:447-452.

6. Mwangangia JM, Mbogoa CM, Muturib EJ, Nzovua JG, Kabiruc EW, Githured JI, et al. Influence of biological and physicochemical characteristics of larval habitats on the body size of Anopheles gambiae mosquitoes (Diptera: Culicidae) along the Kenyan coast. J Vector Borne Dis. 2007; 44:122127.

7. Linenberg I, Christophides GK, Gendrin M. Larval diet affects mosquito development and permissiveness to Plasmodium infection. Scientific report. 2016; 6:38230. doi: 10.1038/srep38230.

8. Araújo M, Gil LH, E-Silva A. Larval food quantity affects development time, survival and adult biological traits that influence the vectorial capacity of Anopheles darlingi under laboratory conditions. Malar J. 2012; 11:261.

9. Moller-Jacobs LL, Murdock CC, Thomas MB. Capacity of mosquitoes to transmit malaria depends on larval environment. Parasit Vectors. 2014; 7:593. 
10. Okech BA, Gouagna, LC, Yan G, Githure JI, Beier JC. Larval habitats of Anopheles gambiaes.s. (Diptera: Culicidae) influences vector competence to Plasmodium falciparum parasites. Malar J. 2007; 6:50. doi:10.1186/1475-2875-6-50.

11. Shapiro LLM, Murdock CC, Jacobs GR, Thomas RJ, Thomas MB. Larval food quantity affects the capacity of adult mosquitoes to transmit human malaria. Proc R Soc B. 2016; 283: 20160298. doi:10.1098/rspb.2016.0298.

12. Joy TK, Arik AJ, Corby-Harris V, Johnson AA, Riehle MA. The impact of larval and adult dietary restriction on lifespan, reproduction and growth in the mosquito Aedes aegypti. Exp. Gerontol. 2010; 45:685-690. doi:10.1016/j.exger.2010.04.009.

13. Timmermann SE and Briegel $\mathrm{H}$. Effect of plant, fungal, and animal diets on mosquito development.Entomol Exp Appl.1996; 80:173-176. doi:10.1111/j.1570-7458.1996.tb00913.x.

14. Merritt RW, Olds EJ, and Walker ED. Feeding behavior, natural food, and nutritional relationships of larval mosquitoes.Annu Rev Entomol.1992; 6:349-376. doi: 10.1146/annurev.en.37.010192.002025.

15. Wotton RS, Chaloner DT, Yardley CA, Merritt RW. Growth of Anopheles mosquito larvae on dietary microbiota in aquatic surface micro layers. Med Vet Entomol. 1997; 11:65-70.

16. Toure AM, Mackey AJ, Wang ZX, Beier JC. Bactericidal effects of sugar-fed antibiotics on resident midgut bacteria of newly emerged Anopheline mosquitoes (Diptera: Culicidae). J Med Entomol. $2003 ; 7: 246-249$.

17. Coon KL, Vogel KJ, Brown MR, Strand MR. Mosquitoes rely on their gut microbiota for development. Mol Ecol. 2014; 23:2727-2739.doi:10.1111/mec.12771.

18. Fayiga AO; Ipinmoroti MO; Chirenje T. Enviromental pollution in Africa, environment, development and sustainability. Springer. 2018; 20:41-73.

19. Fossog BT, Kopya E, Ndo C, Menze-Djantio B, Costantini C, Njiokou F, et al. Water quality and Anopheles gambiae larval tolerance to pyrethroids in the cities of Douala and Yaounde (Cameroon). J Trop Med. 2012; 429817. doi:10.1155/2012/429817.

20. Santolamazza F, Calzetta M, Etang J, Barrese E, Dia I, Caccone A, et al. "Distribution of knock-down resistance mutations in Anopheles gambiae molecular forms in west and west-central Africa." Malar J. 2008; 7:4. doi:10.1186/1475-2875-7-74.

21. Ranson $\mathrm{H}$, Abdallah H, Badolo A, Guelbeogo WM, Kerah-Hinzoumbé $\mathrm{C}$, Yangalbé-Kalnoné $\mathrm{E}$, et al. "Insecticide resistance in Anopheles gambiae: data from the first year of a multi-country study highlight the extent of the problem," Malar J. 2009; 8:299.doi:10.1186/1475-2875-8-299.

22. Riaz MA, Poupardin R, Reynaud S, Strode C, Ranson H, David JP. Impact of glyphosate and benzo[a]pyrene on the tolerance of mosquito larvae to chemical insecticides. Role of detoxification genes in response to xenobiotics. AquatToxicol. 2009; 93(1):61-9. doi:

10.1016/j.aquatox.2009.03.005.

23. Debalke S, Habtewold T, Duchateau L, Christophides GK. The effect of silencing immunity related genes on longevity in a naturally occurring Anopheles arabiensis mosquito population from Southwest Ethiopia. Parasit Vectors. 2019; 12:174. 
24. American Public Health Association. Standard methods for the examination of water and waste water, 18th edition. American Public Health Association, Washington, D.C. 1992.

25. Gerberg EJ. Manual for mosquito rearing and experimental techniques. Bull No. 5. Selma, CA: American Mosquito Control Association, Inc. 1970.

26. Nanci R. Relationship of wing length to adult dry weight in several mosquito species (Diptera: Culicidae). J Med Entomol. 1990; 27:716-719.

27. Habtewold T, Duchateau L, Christophides GK. Flow cytometry analysis of the microbiota associated with the midguts of vector mosquitoes. Parasit Vectors. 2016; 9:167.

28. Duchateau L, Janssen P. The Frailty Model. New York: Springer Verlag; 2008.

29. Hamza AM, Rayah EAE. A qualitative evidence of the breeding sites of Anopheles arabiensis Patton (Diptera: Culicidae) in and around Kassala town, Eastern Sudan. Int J Insect Sci.2016; 8: 6570.doi:10.4137/IJIS.S40071

30. Christiansen-Jucht C, Parham PE, Saddler A, Koella JC, Basáñez MG. Temperature during larval development and adult maintenance influences the survival of Anopheles gambiaes.s. Parasit Vectors. 2014; 7:489. doi:10.1186/s13071-014-0489-3.

31. Wallace JR, Merritt R. Influence of microclimate, food, and predation on Anopheles quadrimaculatus (Diptera: Culicidae) growth and development rate, survivorship, and adult size in a Michigan pond. Environ Entomol. 1999; 28:233-239.

32. Emide B, Kisinza WN, Mmbando BP, Malima R, Mosha FW. Effect of physicochemical parameters on Anopheles and Culex mosquito larvae abundance in different breeding sites in a rural setting of Muheza, Tanzania. Parasit Vectors. 2017; 10:304. doi:10.1186/s13071-017-2238-x.

33. Chouaia B, Rossi P, Epis S, Mosca M, Ricci I, Damiani C, et al. Delayed larval development in Anopheles mosquitoes deprived of Asaia bacterial symbionts. BMC Microbiol. 2012; 12:S2.

34. Mitraka E, Stathopoulos S, Siden-Kiamos I, Christophides GK, Louis C. Asaia accelerates larval development of Anopheles gambiae. Pathog Glob Health. 2013; 107:305-311. doi: 10.1179/2047773213Y.0000000106.

35. Pfaehler O, Oulo DO, Gouagna LC, Githure J, Guerin PM. Influence of soil quality in the larval habitat on development of Anopheles gambiae Giles. J Vector Ecol. 2006; 31:400-405. doi: 10.3376/10811710(2006)31[400:IOSQIT]2.0.C0;2.

36. Tun-Lin W, Burkot TR, Kay H. Effects of temperature and larval diet on development rates and survival of the dengue vector Aedes aegypti in North Queensland, Australia. Med Vet Entomol. 2000; 14:31-37. doi:10.1046/j.1365-2915.2000.00207.x.

37. Dida GO, Anyona DN, Abuom PO, Akoko D, Adoka SO, Matano AS, et al. Spatial distribution and habitat characterization of mosquito species during the dry season along the Mara River and its tributaries, in Kenya and Tanzania. Infect Dis Poverty. 2018; 7:2. doi:10.1186/s40249-017-0385-0.

38. Dejenie T, Yohannes M, AssmelashT. Characterization of Mosquito Breeding Sites in and in the Vicinity of Tigray Microdams. Ethiop J Health Sci. 2011; 21:57-66.doi:10.4314/ejhs.v21i1.69045. 
39. Lounibos B, Nishimura N, Conn J, Lourenco-deOliveira R. Mem Inst Oswaldo Cruz. 1995; 90: 769-74.

40. Ameneshewa B and Service M. The relationship between female body size and survival rate of the malaria vector Anopheles arabiensis in Ethiopia. Med Vet Entomol. 1996; 10:170-172. dio:10.1111/j.1365-2915.1996.tb00724.x.

41. Lehmann T, Dalton R, Kim EH, Dahl E, Diabate A, Dabire R, et al. Genetic contribution to variation in larval development time, adult size, and longevity of starved adults of Anopheles gambiae. Infect Genet Evol. 2006; 6:410-416.

\section{Figures}




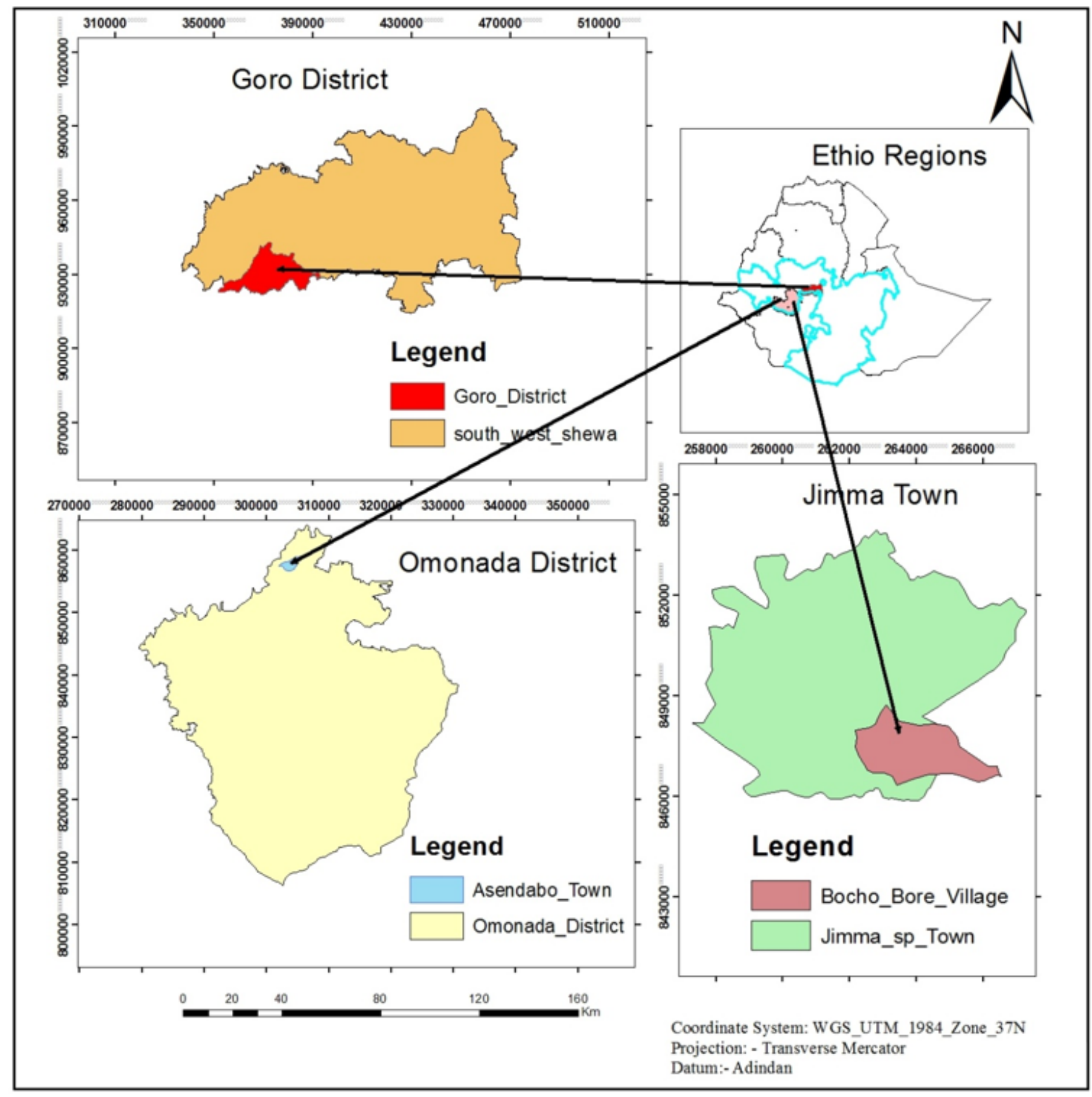

Figure 1

Map showing larval breeding sites where rearing water samples were collected 

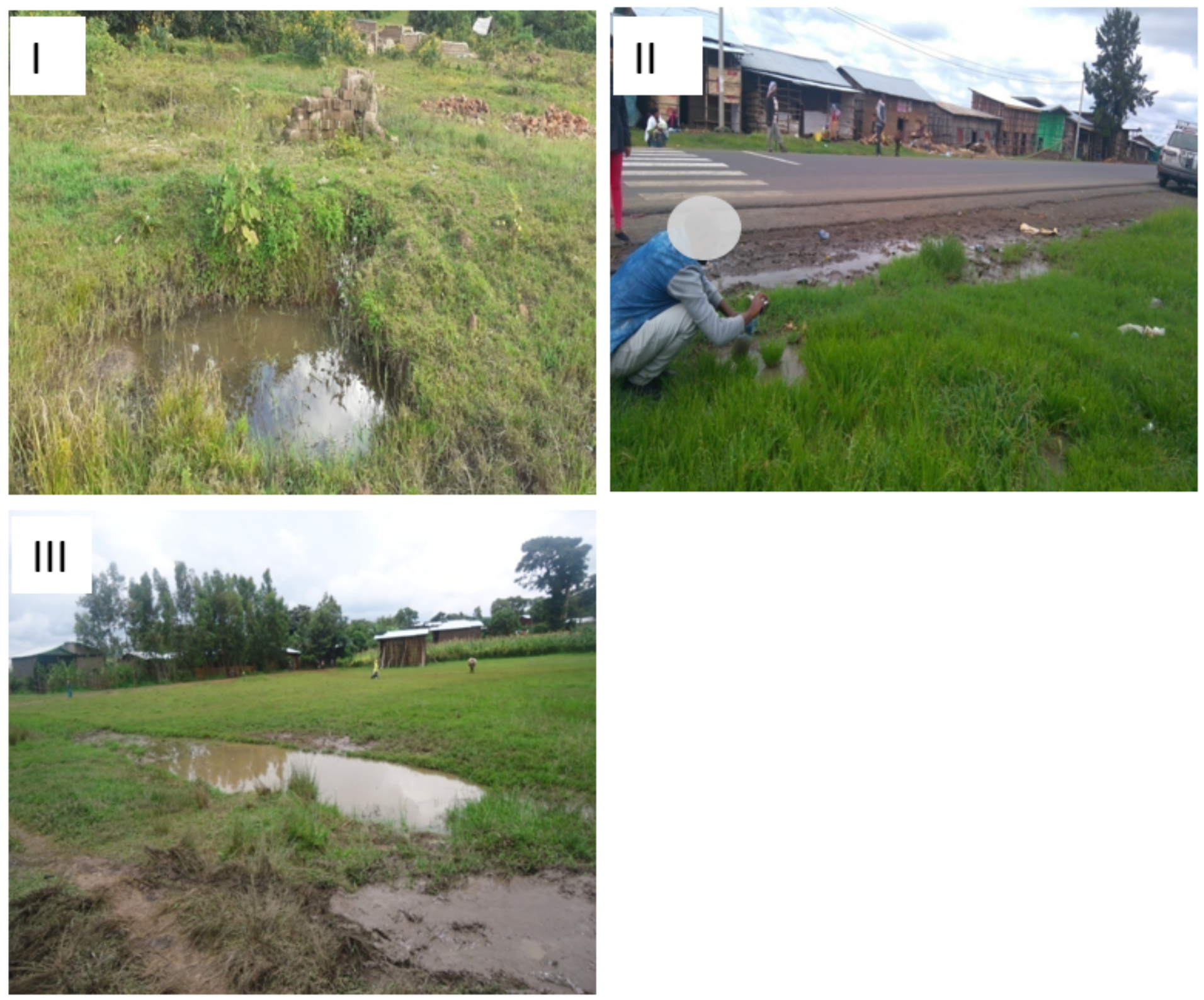

Figure 2

Breeding sites from where larval rearing water samples collected representing brick-pit pool at Jimma town (I), flooded farmland at Asendabo (II) and roadside pool at Wolkite (III). 
Unboiled

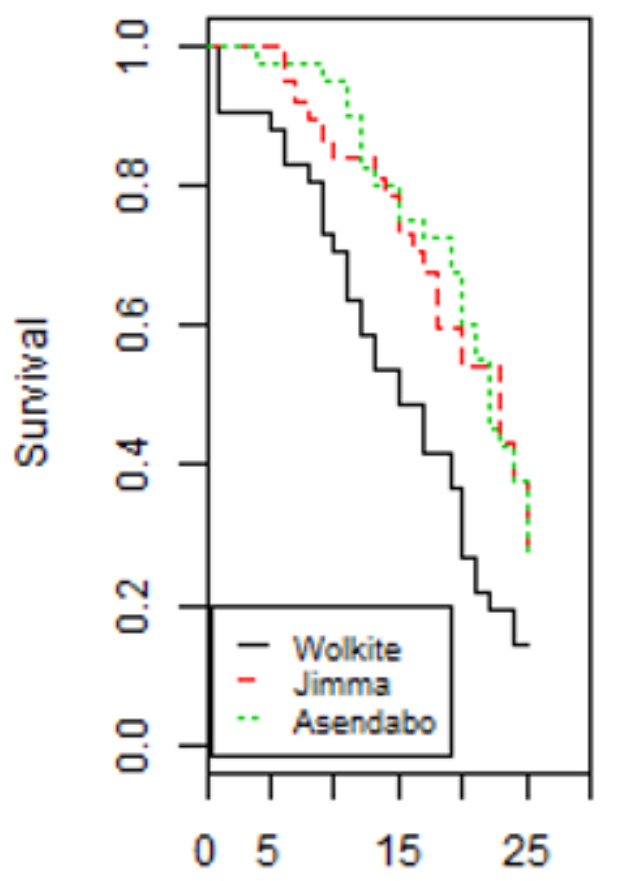

Time (in days)
Boiled

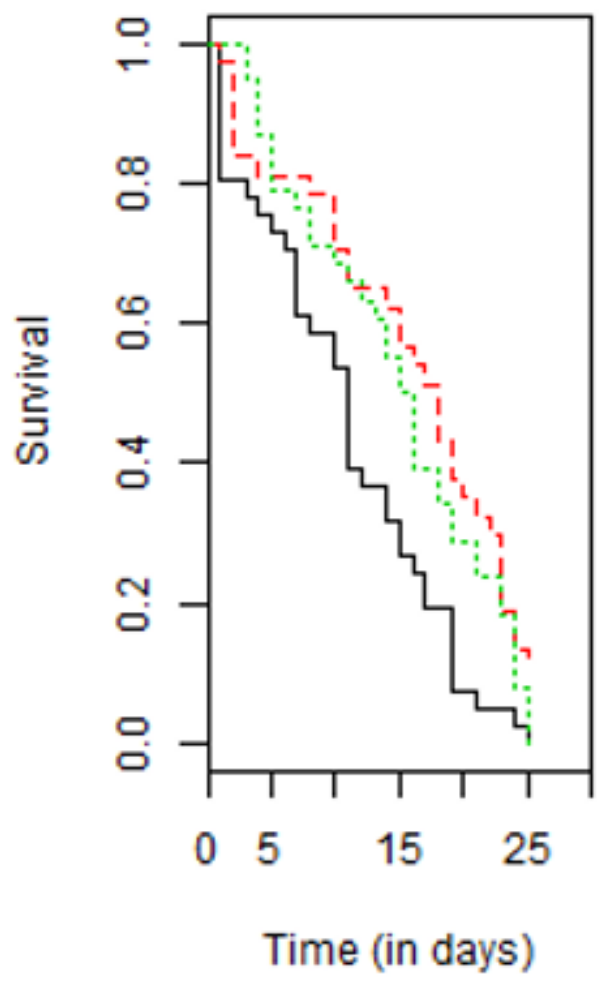

\section{Figure 3}

Survival as a function of time for the naive mosquitoes for the three sites (Wolkite, Jimma and Asendabo) and water boiled or unboiled. 


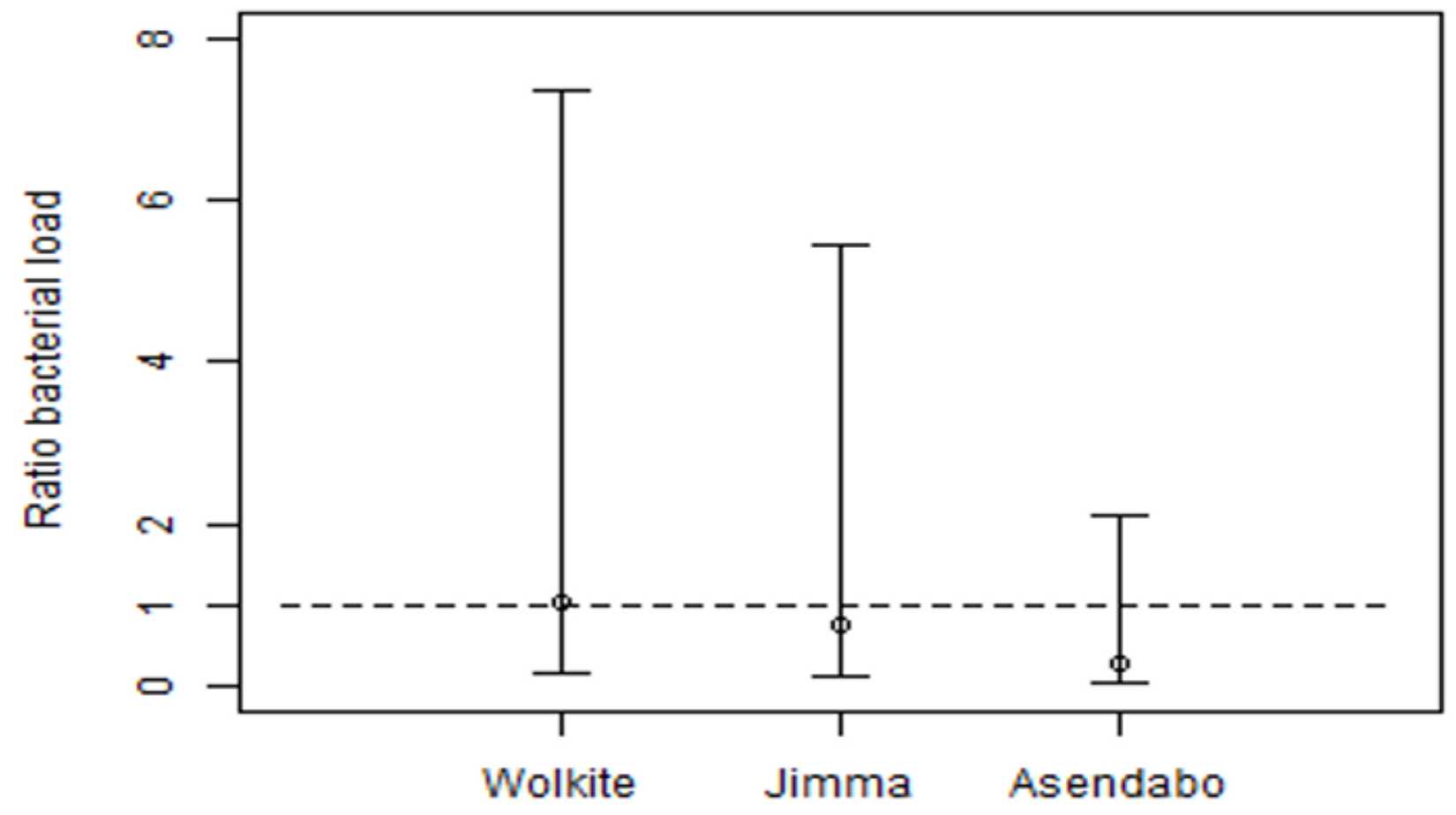

Figure 4

Ratio of adult gut bacterial load ( $95 \%$ confidence interval) of mosquitoes in boiled versus unboiled water in the three sites. 

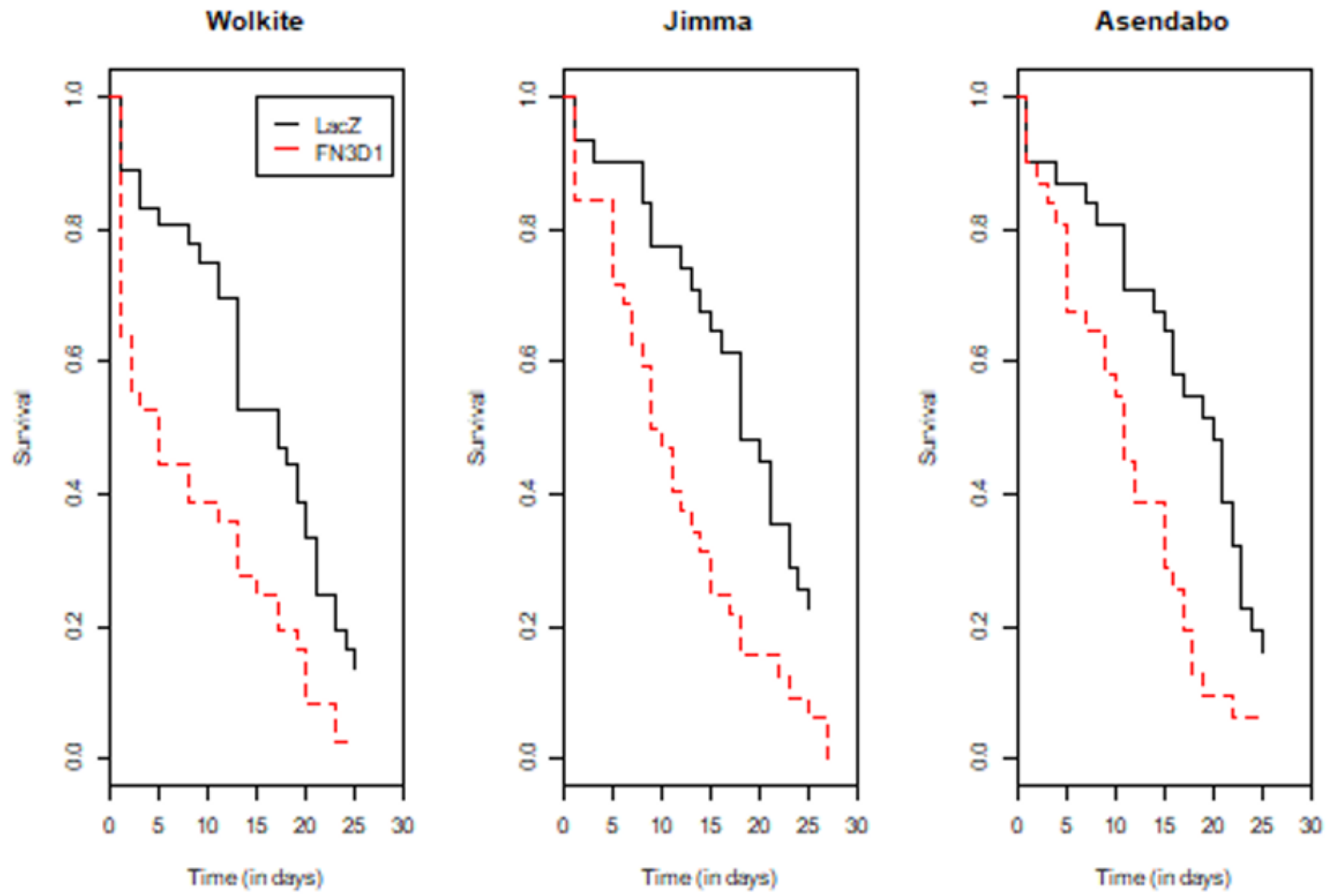

Figure 5

Survival as a function of time for the control LacZ and target FN3D1 gene silenced mosquitoes at the three different sites. 


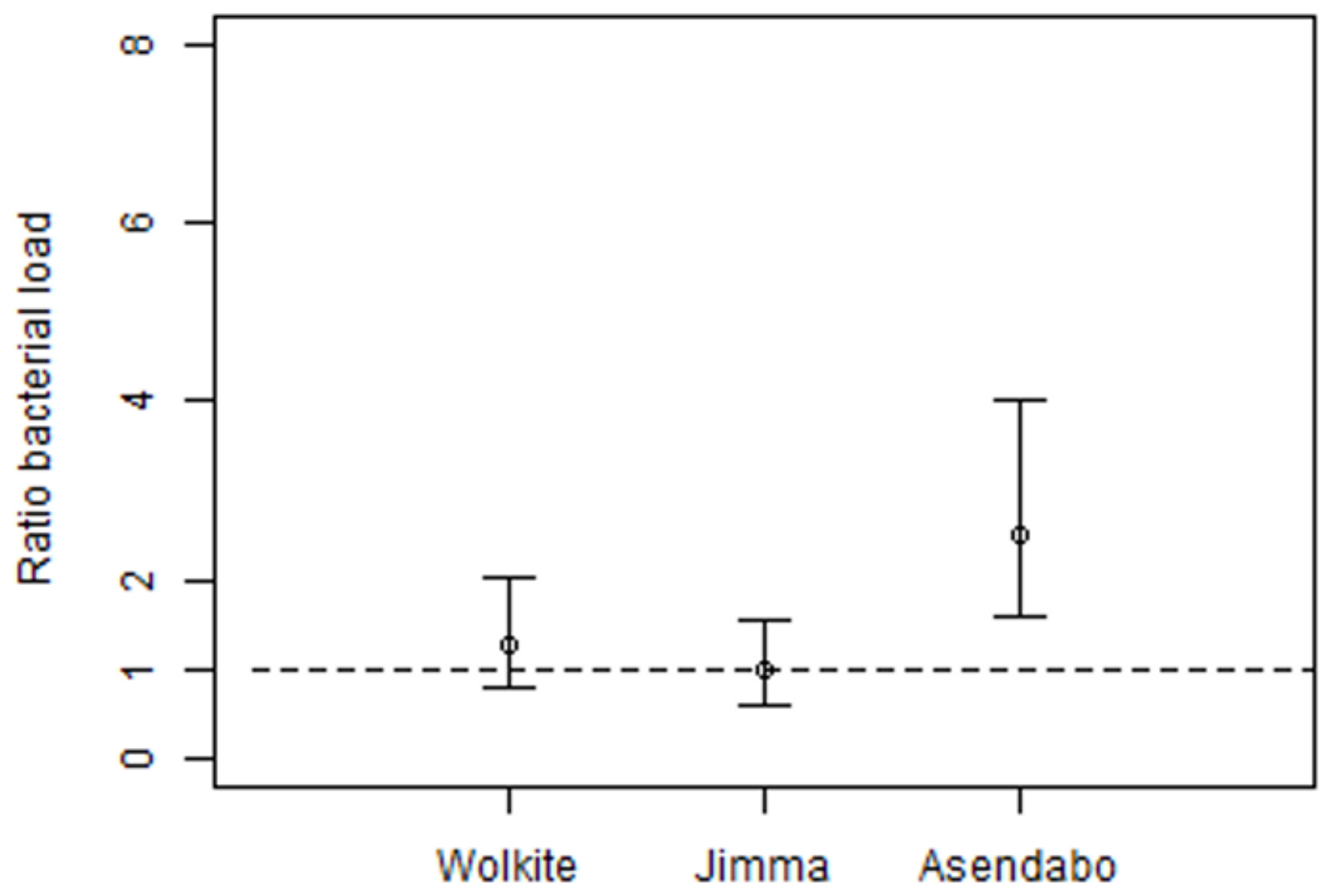

Figure 6

Ratio of adult gut bacterial load (95\% confidence interval) in FN3D1 silenced versus LacZ silenced mosquitoes in the three sites.

\section{Supplementary Files}

This is a list of supplementary files associated with this preprint. Click to download.

- 20130704112423.jpg 